\title{
Early L-T4 intervention improves fetal heart development in pregnant rats with subclinical hypothyroidism rats by activating BMP4/Smad4 signaling pathway
}

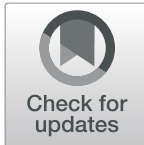

D. Xue $e^{1,2}$, J. L. Sun ${ }^{3}$ and J. Yang ${ }^{1 *}$

\begin{abstract}
Background: It is unclear whether the offspring of subclinical hypothyroidism (SCH) pregnant rats still have abnormal cardiac development, and whether early intervention with L-T4 can improve the abnormality of these offspring. Therefore, the aim of this study was to investigate the effect of early L-T4 intervention on the heart development of offspring of $\mathrm{SCH}$ pregnant rats and its possible molecular mechanism.
\end{abstract}

Methods: Eighty female Wistar rats were randomly divided into Sham group (placebo control), SCH group, LT4-E10 group (L-T4 treatment started on the 10th day of gestation), and LT4-E13 group (L-T4 treatment started on the 13th day of gestation). Each group was further divided into E16 (16th day of gestation), E18 (18th day of gestation), P5 (5th day postnatal day), and P10 (10th day postnatal day) subgroups. The levels of serum TT4 and TSH, the ratio of heart weight to body weight of offspring rats, the expression of metabolic enzymes, and the histopathology of cardiomyocytes were determined. To elucidate the effects of L-T4 on cardiac development of offspring of SCH pregnant rats, the expression levels of GATA4, Nkx2-5 and proteins involved in BMP4/Smad4 signaling pathway were detected by immunohistochemistry, real time quantitative polymerase chain reaction and Western blotting to elucidate the molecular mechanism of L-T4 regulating the heart development of the offspring of SCH pregnant rats.

Results: Compared with Sham group, serum TSH was significantly increased in SCH pregnant rats. Moreover, early L-T4 intervention significantly reduced the levels of serum TSH. Compared with the offspring in the SCH group, early L-T4 intervention significantly increased the heart weight, heart weight to body weight ratio, the activities of succinate dehydrogenase (SDH), $\mathrm{Na}^{+} / \mathrm{K}^{+}$-ATPase and $\mathrm{Ca}^{2+}$-ATPase, but reduced myocardial cell shrinkage and nuclear staining, hyperemia/congestion and vacuolar degeneration. In addition, early L-T4 intervention not only significantly increased the mRNA and protein expression of Gata4 and Nkx2-5, but also increased the protein expression involved in BMP4/Smad4 signal pathway in myocardium of the offspring of SCH pregnant rats.

(Continued on next page)

\footnotetext{
*Correspondence: junyang63@sina.com

'Department of Cardiovascular Ultrasound, The First Hospital of China

Medical University, No.115, Nanjing Road, HePing District, Shenyang 110001,

China

Full list of author information is available at the end of the article
}

(c) The Author(s). 2020 Open Access This article is licensed under a Creative Commons Attribution 4.0 International License, which permits use, sharing, adaptation, distribution and reproduction in any medium or format, as long as you give appropriate credit to the original author(s) and the source, provide a link to the Creative Commons licence, and indicate if changes were made. The images or other third party material in this article are included in the article's Creative Commons licence, unless indicated otherwise in a credit line to the material. If material is not included in the article's Creative Commons licence and your intended use is not permitted by statutory regulation or exceeds the permitted use, you will need to obtain permission directly from the copyright holder. To view a copy of this licence, visit http://creativecommons.org/licenses/by/4.0/ The Creative Commons Public Domain Dedication waiver (http://creativecommons.org/publicdomain/zero/1.0/) applies to the data made available in this article, unless otherwise stated in a credit line to the data. 
(Continued from previous page)

Conclusions: Early L-T4 intervention can regulate the cardiac development of the offspring of SCH pregnant rats by activating BMP4/Smad4 signaling pathway and increasing the expression of Gata4 and Nkx2-5 proteins.

Keywords: Subclinical hypothyroidism, Cardiac development, Pregnant rats, L-T4, BMP4/Smad4 signaling pathway

\section{Background}

Subclinical hypothyroidism ( $\mathrm{SCH}$ ) is one of the most common thyroid diseases during pregnancy, affecting 2 to $3 \%$ of the global population. $\mathrm{SCH}$ was defined as increased serum thyroid-stimulating hormone (TSH) during pregnancy, but the level of free thyroxine (FT4) is normal [1]. Pregnancy has a great influence on the thyroid function of pregnant women. During pregnancy, human chorionic gonadotropin (HCG) weakly binds and stimulates TSH receptor and stimulates thyroid to produce more thyroxine. Meanwhile, the volume of thyroid increases by 10 to $40 \%$, and the demand for thyroxine and iodine also increases by $50 \%$, which will inevitably lead to hypothyroidism in the third trimester of pregnancy. Patients diagnosed with $\mathrm{SCH}$ before pregnancy have more severe symptoms of thyroid hormone deficiency during pregnancy [2]. It is known that poor control of SCH during pregnancy is related to pregnancy complications and growth retardation of offspring. In addition, women with hypothyroidism have an increased risk of hypertension and fetal death. These data indicate that there is a certain relationship between pregnant women with $\mathrm{SCH}$ and the risk of fetal disease [3].

Since the cardiovascular system is rich in thyroid receptor, it is relatively sensitive to the change of TSH levels [4]. Previous studies have showed that TSH levels above $7.0 \mathrm{mIU} / \mathrm{L}$ led to abnormalities in lipid metabolism, oxidative stress and endothelial function, thereby increasing the risk of atherosclerosis and congestive heart failure. In addition, patients with $\mathrm{SCH}$ under 65 years of age were associated with increased risk of coronary heart disease, heart failure, and cerebrovascular diseases. Patients with TSH levels above $10 \mathrm{mIU} / \mathrm{L}$ have a higher risk of heart failure with lower ejection fraction compared to participants with normal thyroid function [5]. The left ventricular diastolic dysfunction caused by $\mathrm{SCH}$ may be related to endothelial dysfunction, arterial stiffness and inflammation [6]. Another clinical study indicated that patients with $\mathrm{SCH}$ often had a slower heart rate and shorter corrected QT, which may be closely related to cardiac systolic dysfunction [7]. Longer P-wave duration, longer PR interval and decreased voltage were observed in patients with $\mathrm{SCH}$. In addition, age and gender were known to be closely related to the occurrence of $\mathrm{SCH}$ [8]. However, it is still unclear the effect of pregnant women with $\mathrm{SCH}$ on fetal heart development and its possible molecular mechanism.
Although it is well known that women with hypothyroidism should increase the dose of levothyroxine during pregnancy, the exact timing and dose are not clear. A previous study found that women with hypothyroidism took administrated $150 \mu \mathrm{g} /$ day of levothyroxine, a manufactured form of the thyroid hormone thyroxine (T4), during13 weeks of pregnancy, which can lead to an increase in TSH or a decrease in FT4 [9]. It has been confirmed that the demand for exogenous L-T4 dose of most pregnant women increase from 25 to $30 \%$ during the first 4 to 6 weeks of pregnancy and gradually increased within 16 to 20 weeks of pregnancy, and then stabilize until delivery [10]. It was reported that compared with healthy people, the left ventricular systolic and diastolic function of $\mathrm{SCH}$ patients was slightly affected. Moreover, L-T4 treatment reversed the change of left ventricular systolic and diastolic function of SCH patients, but has no significant effect on systolic pressure [11]. A similar study also found that for children with hypothyroidism and ventricular diastolic dysfunction, L-T4 treatment can significantly improve left ventricular dysfunction [12]. However, the effects of L-T4 on the fetal heart development of pregnant women with $\mathrm{SCH}$ and its possible mechanism are still unknown. Therefore, the aim of this preclinical study was to investigate the effect of L-T4 treatment on the fetal heart development in $\mathrm{SCH}$ pregnant rats and to explore its possible molecular mechanism.

\section{Methods \\ Animals and groups}

Eighty female Wistar rats, aged 6-8 weeks and weighing 180-200 g, were purchased from the Benxi Changsheng Biotechnology Co., Ltd. The animals were kept in the Experimental Animal Department of the Northern Theater General Hospital. The ambient temperature was maintained at $21-22^{\circ} \mathrm{C}$ with $50-60 \%$ relative humidity. All rats were maintained under a 12:12-h light/dark cycle, with access to food and water ad libitum. Eighty rats were randomly divided into Sham group (placebo control), SCH group, LT4-E10 group (L-T4 treatment started on the 10th day of gestation), and LT4-E13 group (L-T4 treatment started on the 13th day of gestation). Each group was further divided into E16 (16th day of gestation), E18 (18th day of gestation), P5 (5th day postnatal day), and P10 (5th day postnatal day) subgroups. The animal experiment procedure was approved 
by the Animal Care and Use Committee of the General Hospital of Northern Theater Command, which complied with the national guidelines on the protection and use of laboratory animals.

\section{Establishment of the $\mathrm{SCH}$ rat model}

Establishment of the $\mathrm{SCH}$ rat model refers to the previously literature [13].The rats were injected with $3 \%$ pentobarbital sodium $(0.1 \mathrm{~mL} / 100 \mathrm{~g})$ and underwent thyroidectomy, while Sham group rats underwent sham thyroid surgery. The rats were fed normally for $4 \mathrm{w}$ after operation, then the blood was collected from the retroorbital venous plexus, and serum TSH and TT4 were detected. When serum TSH levels were higher than that in Sham group, the TT4 levels were lower than that in Sham group, confirming the successful establishment of the $\mathrm{SCH}$ rat model. Four weeks after surgery, rats in the $\mathrm{SCH}$ group were injected subcutaneously with Lthyroxine (L-T4, Sigma, USA) $1.0 \mu \mathrm{g} / 100 \mathrm{~g} /$ day on the neck. Sham group rats were injected subcutaneously with physiological saline $(50 \mu \mathrm{L} / 100 \mathrm{~g} /$ day $)$ on the neck. Calcium lactate $(0.1 \% \mathrm{w} / \mathrm{v})$ was added to the drinking water for all rats after surgery. Nine days later, all rats were mated with normal male rats (male: female $=1: 2$ ). The pregnant rats were then kept in single cages until delivery. The day of vaginal plus was confirmed by microscopic observation and designated as E0. Serum and tissue samples were collected at E16, E18, P5 and P10. At the end of the experiment, all rats were anesthetized with pentobarbital $(50 \mathrm{mg} / \mathrm{kg}$, intraperitoneal) and euthanized by thoracotomy and hearts removal.

\section{Measurement of TT4 and TSH}

Blood samples obtained from the rats were immediately centrifuged at $13,000 \mathrm{~g}$ for $15 \mathrm{~min}$ and stored at $-80^{\circ} \mathrm{C}$ for measurement of serum TT4 ( ${ }^{\#}$ CEA452Ge, Youersheng, China) and TSH ( ${ }^{*}$ CEA463Ra, Youersheng, China) using a supersensitive chemiluminescence immunoassay.

\section{ATPase activity analysis}

The ATPase activity was detected using an ultramicro $\mathrm{Ca}^{2+}$-ATPase kit and $\mathrm{Na}^{+} / \mathrm{K}^{+}$-ATPase kit ( ${ }^{\#} \mathrm{~A} 070$, Nanjing Jiancheng Bioengineering Institute, China) according to the manufacturer's instructions. The succinate dehydrogenase (SDH) activity was measured by kit(A022, Nanjing Jiancheng Bioengineering Institute, China). Protein content was measured with a Coomassie blue protein assay kit ( ${ }^{\#}$ WLA004a, wanleibio, China). ATPase activity was expressed as mol Pi liberated per mg protein per hour ( $\mathrm{mol} \mathrm{Pi} /(\mathrm{mg}$ prot.hr)).

\section{RNA isolation and quantitative real-time PCR}

RNA was extracted from heart tissues from each group using TRIzol (Life Tech). First strand of cDNA was synthesized using total RNA and RT-PCR was carried out by TaqMan expression assays, and $\beta$-actin $\left({ }^{\#}\right.$ WL01845, wanleibio, China) was used as a internal reference. The sequences for Nkx2-5, Gata4, BMP4, Smad4 and GAPDH were performed through the ABI PRISM system. Primer sequences are shown: Bmp4 $\mathrm{F}$ 5' -ATCGTTACC TCAAGGGAGTGGA-3'; Bmp4 R 5' ATCGTTACCTCAAGGGAGTGGA-3'; Samd4 F 5'CGTTCACGAGGCATTTAC-3'; Samd4 R $5^{\prime}$ GGGAGGGAGTTGGACTG-3'; Nkx2-5 F $5{ }^{\prime}$-TGGA CAAAGCCGAGACAGAC-3'; Nkx2-5 R $5^{\prime}$-TCAG CGGGCGACAGGTA-3'; Gata4 F 5'-AAACGGAAGC CCAAGAAT-3'; Gata4 R 5'-GCTGCTGTGCCCATA GTGAG-3'; $\beta$-actin F $5^{\prime}$-GGAGATTACTGCCCTGGC TCCTAGC-3'; $\beta$-actin R 5'-GGCCGGACTCATCGTA CTCCTGCTT. Reactions were performed in a total volume of $20 \mu \mathrm{L}$ and gene expression was determined by SYBR Premix Ex Taq TM II (TaKaRa Biotechnology Co., Ltd.) in accordance with the manufacturer's instructions. Reactions began with a $10 \mathrm{~s}$ hot activation of Taq polymerase at $95^{\circ} \mathrm{C}$, followed by $40-45$ cycles of amplification in three steps (denaturation at $95^{\circ} \mathrm{C}$ for $5 \mathrm{~s}, 30 \mathrm{~s}$ annealing at $60^{\circ} \mathrm{C}$ and $30 \mathrm{~s}$ extension at $72^{\circ} \mathrm{C}$ ). The mRNA expression was measured as a ratio to $\beta$-actin.

\section{Immunohistochemistry staining}

Immunohistochemistry staining was performed to localize Nkx2-5 (1:500, "A12688, wanleibio, China), Gata4 (1:1000, "WL01293, wanleibio, China), BMP4 (1: 500, "WL02806, wanleibio, China) and Smad4 (1:300, ${ }^{\#}$ WL02049, wanleibio, China). Heart tissues were routinely embedded in paraffin, and sectioned at a $3-5 \mu \mathrm{m}$ thickness. All sections were dewaxed, and incubated with $0.3 \% \mathrm{H} 2 \mathrm{O} 2$ for $10 \mathrm{~min}$. The antigen was repaired by heating $0.03 \mathrm{M}$ citrate buffer ( $\mathrm{pH} 6.0$ ) for $40 \mathrm{~min}$ at $95^{\circ} \mathrm{C}$, and then incubated with $5 \%$ goat serum albumin for $20 \mathrm{~min}$ to block the non-specific binding sites. All sections were incubated with primary antibody overnight at $4{ }^{\circ} \mathrm{C}$ in a wet box and stained with sheep anti-rabbit IgG-HRP secondary antibodies (Abcam, UK). The sections were stained using 3,3-diaminobenzidine (DAB) (Sigma, USA) and counterstained with hematoxylin solution. Tissue sections without primary antibodies were the negative controls. Finally, samples were observed and photographed under a microscope.

\section{Western blotting}

Western blotting was performed as described previously [14]. Heart samples were lysed in complete RIPA buffer (10 mM Tris- $\mathrm{HCl} \mathrm{pH} 7.4,150 \mathrm{mM} \mathrm{NaCl}, 1 \% \mathrm{NP} 40,0.1 \%$ sodium dodecyl sulfate, $1 \mathrm{mM}$ phenylmethylsulfonyl fluoride and $1 \times$ protease inhibitor cocktail [Roche]) and homogenized using a Sonic Dismembrator 100. The concentration of tissue protein was detected using a 
BCA protein concentration test kit $\left({ }^{\#}\right.$ WLA004, wanleibio, China), and equal amounts of soluble protein were separated on $10 \%$ polyacrylamide gels, transferred onto a nitrocellulose membrane, and followed by routine western blot analysis. Primary antibody: Nkx2-5 (1:500, ${ }^{\#}$ A12688, wanleibio, China), Gata4 (1:1000, ${ }^{*}$ WL01293, wanleibio, China), BMP4 (1:500, "WL02806, wanleibio, China) and Smad4 (1:300, "WL02049, wanleibio, China). Proteins were visualized using a ClarityTM Western ECL Substrate ( ${ }^{\#}$ WLA003; wanleibio, China) and a Tanon 5200 Full automatic chemiluminescence image analysis system (Tanon Science and Technology Co., Ltd., Shanghai, China).

\section{Statistical analysis}

Statistical analysis was performed using SPSS 20.0 statistical software (IBM Corp., Armonk, NY, USA). Variables are expressed as the means \pm standard error of the mean (SEM). Data were analyzed using t-tests and one-way ANOVA. Statistical significance was reached at a twosided $p<0.05$.

\section{Results}

Effects of L-T4 on serum TSH and TT4 expression in the offspring of $\mathrm{SCH}$ pregnant rats

In order to evaluate the thyroid function of $\mathrm{SCH}$ pregnant rats, the expression levels of serum TT4 and TSH of all pregnant rats were measured. The serum TSH level in SCH group was significantly higher than that in the Sham group (Fig. 1a, $p<0.05$ ). There was no significant difference in TT4 expression level between the two groups, confirming the successful establishment of the $\mathrm{SCH}$ rat model (Fig. 1b). Interestingly, in the LT4-E10 and LT4-E13 groups, L-T4 treatment significantly reduced serum TSH expression level in $\mathrm{SCH}$ pregnant rats (Fig. 1a, compared to $\mathrm{SCH}$ group, $p<0.05$ ). Moreover, there was no significant difference in the TT4 expression level between SCH, LT4-E10 and LT4-E13 groups. The results indicated that L-T4 treatment would affect the serum TSH expression levels in $\mathrm{SCH}$ pregnant rats, but did not change the expression level of TT4.

\section{L-T4 treatment promoted cardiac development in the offspring of $\mathrm{SCH}$ pregnant rats}

To explore the effect of L-T4 on the heart development of the offspring of $\mathrm{SCH}$ pregnant rats, the heart weight and the ratio of heart weight to body (heart/body) weight were examined. The results showed that the heart weight and the heart/body weight of the offspring in the $\mathrm{SCH}$ group were significantly lower than that in the Sham group. Furthermore, in the LT4-E10 and LT4E13 groups, L-T4 treatment significantly increased the heart weight and heart/body weight of the offspring of $\mathrm{SCH}$ pregnant rats (Fig. 2, compared to $\mathrm{SCH}$ group, $p<$ 0.05 ). The results suggested that early administration of L-T4 can promote the heart development of the offspring of $\mathrm{SCH}$ pregnant rats.

\section{L-T4 treatment improved the metabolic function of cardiomyocytes in the offspring of $\mathrm{SCH}$ pregnant rats}

To clarify the effects of L-T4 on the metabolic ability of cardiomyocytes of the offspring of $\mathrm{SCH}$ pregnant rats, the activities of SDH, $\mathrm{Na}^{+} / \mathrm{K}^{+}$-ATPase and $\mathrm{Ca}^{2+}$-ATPase were detected. The results showed that compared to Sham group, the activities of SDH, $\mathrm{Na}^{+} / \mathrm{K}^{+}$-ATPase and $\mathrm{Ca}^{2+}$-ATPase of the offspring were significantly decreased in the SCH group at E16, E18, P5 and P10. In the LT4-E10 and LT4-E13 groups, L-T4 treatment significantly increased the activities of SDH, $\mathrm{Na}+/ \mathrm{K}+-\mathrm{ATP}$ and $\mathrm{Ca} 2+-\mathrm{ATP}$ (Fig. 3, compared to $\mathrm{SCH}$ group, $p<$ $0.05)$. The results suggested that $\mathrm{L}-\mathrm{T} 4$ treatment regulated the cardiac development of the offspring of $\mathrm{SCH}$
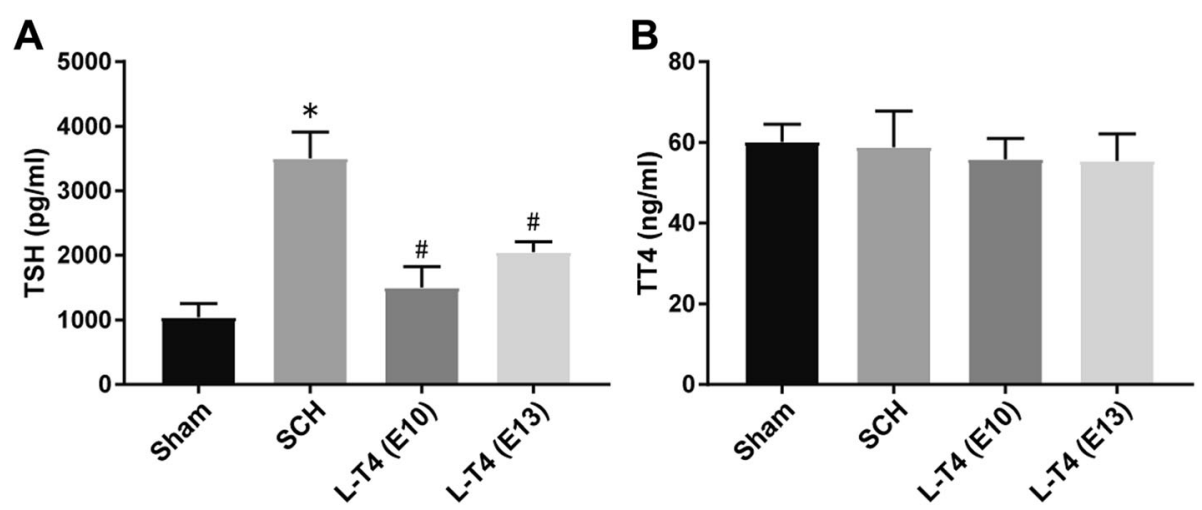

Fig. 1 Effects of L-T4 treatment on the expression levels of serum TSH and TT4 in the offspring of SCH pregnant rats. a TSH expression level of pregnant rats in the Sham, SCH, LT4-E10 (L-T4 treatment started on the 10th day of gestation), and LT4-E13 (L-T4 treatment started on the 13th day of gestation) groups. There were 20 rats in each group. b T4 expression level of pregnant rats in each group. ${ }^{*} p<0.05$ vs Sham group; ${ }^{\#} p<0.05$ vs SCH group 

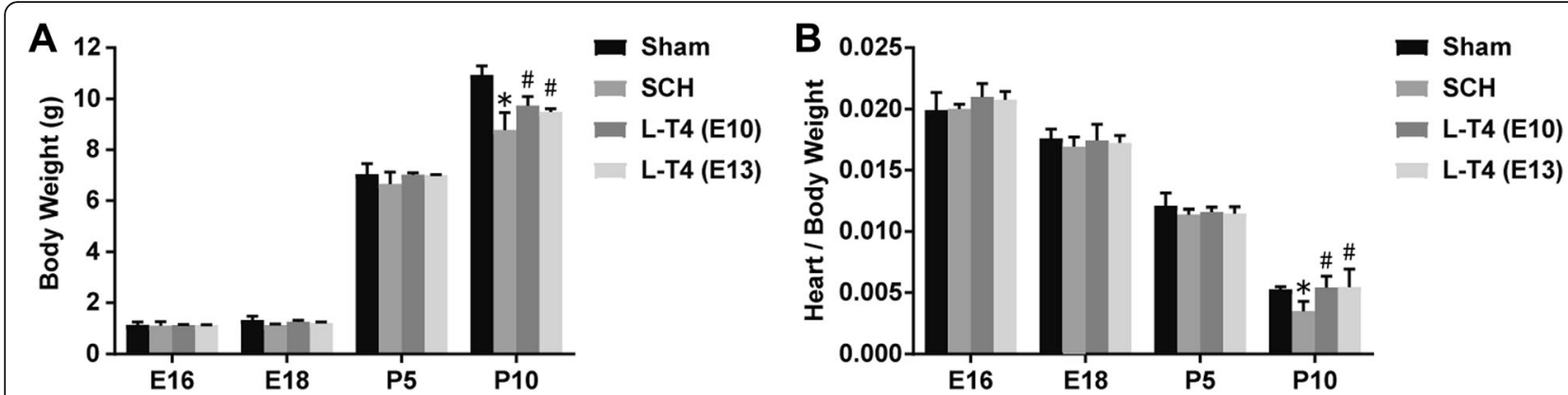

Fig. $\mathbf{2} \mathrm{L}-\mathrm{T} 4$ promotes cardiac development in the offspring of SCH pregnant rats. a Body weight of the offspring of SCH pregnant rats. $\mathbf{b}$ The ratio of heart weight to body weight (Heart/Body Weight) of the offspring of SCH pregnant rats. Results are expressed as the mean \pm SEM ( $n=5$ per group). ${ }^{*} p<0.05$ vs Sham group; ${ }^{\#} p<0.05$ vs SCH group

pregnant rats by increasing the metabolic function of the cardiomyocytes.

\section{L-T4 treatment attenuated cardiac tissue injury of the offspring of SCH pregnant rats}

The results of histopathological staining showed that the cardiomyocytes of the offspring in the Sham group were orderly arranged, and the structure of cardiomyocytes was clear and intact (Fig. 4). However, the cardiomyocytes of the offspring in the $\mathrm{SCH}$ group showed wrinkled, hyperchromatic and loosely arranged structures, with obvious hyperemia, congestion and vacuolar degeneration cell shrinkage, hyperchromatic nuclei, local hyperemia/congestion and vacuolar degeneration. Moreover, in the LT4-E10 and LT4-E13 groups, the degree of cardiomyocyte degeneration, inter-tissue congestion and vacuolar degeneration gradually improved after L-T4 treatment. The results suggested that L-T4 treatment during pregnancy can improve the pathological changes of the heart tissue of the offspring of $\mathrm{SCH}$ pregnant rats.

\section{L-T4 promoted the expression of cardiac development proteins in the offspring of $\mathrm{SCH}$ pregnant rats}

Real-time quantitative PCR, immunohistochemistry and Western blotting were used to detect the expression of mRNAs and proteins related to cardiac development and differentiation of the offspring of $\mathrm{SCH}$ pregnant rats.
The results showed that the expression levels of Nkx2-5 and Gata4 mRNA of the offspring in the $\mathrm{SCH}$ group was significantly lower than that in the Sham group. Furthermore, in the LT4-E10 and LT4-E13 groups, L-T4 treatment significantly increased the expression levels of Nkx2-5 and Gata4 mRNA in the myocardium of the offspring (Fig. 5a-b, compared to $\mathrm{SCH}$ group, $p<0.05$ ). Western blotting analysis further confirmed the results that the expression levels of Gata4 and Nkx2-5 protein in the myocardium of the offspring in the $\mathrm{SCH}$ group was significantly lower than that in the Sham group, while LT4 treatment further significantly increased the expression levels of Gata4 and Nkx2-5 protein in the myocardium of the offspring in the LT4-E10 and LT4-E13 groups (Fig. 5c-d, compared to $\mathrm{SCH}$ group, $p<0.05$ ). Similarly, the results of immunohistochemical staining showed that Gata4 and Nkx2-5 proteins were mainly expressed in the nucleus of heart cells. Compared to Sham group, the number of Gata4- and Nkx2-5-positive cells of the offspring in the $\mathrm{SCH}$ group were significantly reduced. Moreover, L-T4 treatment significantly increased the number of Gata4- and Nkx2-5-positive cells of the offspring in the LT4-E10 and LT4-E13 groups (Fig. 5e-f, compared to $\mathrm{SCH}$ group, $p<0.05)$. The results suggested that L-T4 treatment can regulate the cardiac development of the offspring of $\mathrm{SCH}$ pregnant rats by increasing the expression of Gata 4 and Nkx2-5 proteins.

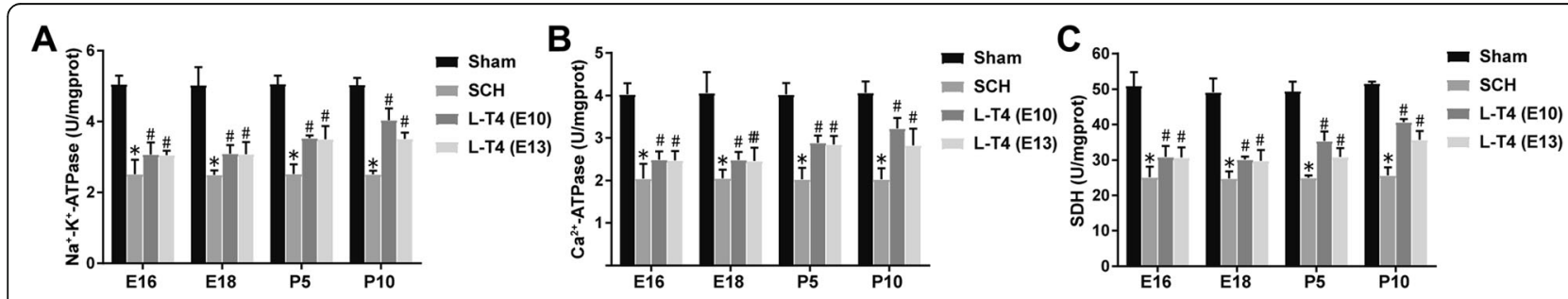

Fig. $3 \mathrm{~L}$-T4 treatment improved the metabolic function of cardiomyocytes in the offspring of SCH pregnant rats. (a) Na ${ }^{+} / \mathrm{K}^{+}$-ATPase activity (b) $\mathrm{Ca}^{2+}$-ATPase activity $(\mathbf{c})$ SDH activity. All experiments were repeated at least three times. Data were expressed as the mean \pm SEM $(n=5$ per group). * $p<0.05$ vs Sham group; ${ }^{\#} p<0.05$ vs SCH group 


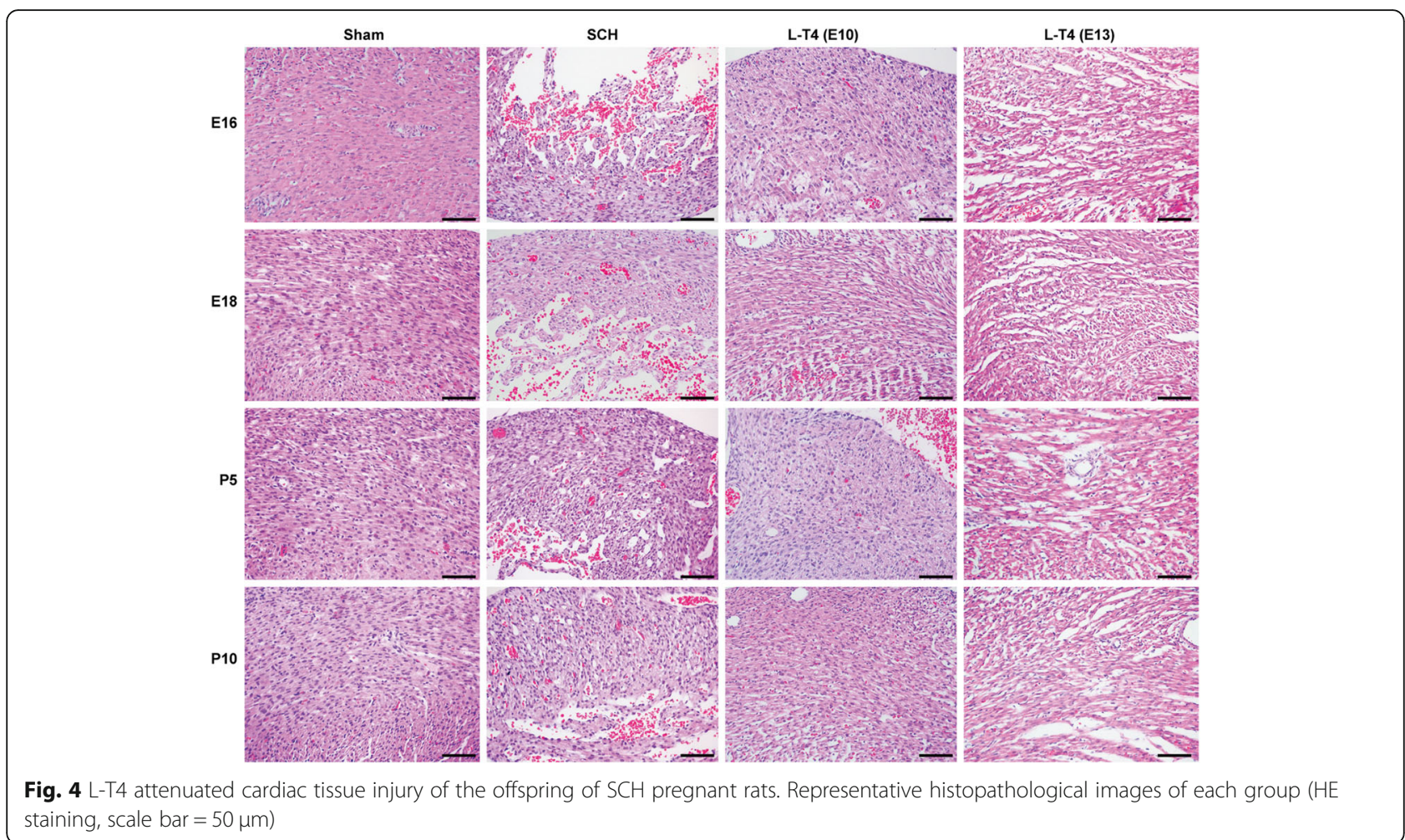

L-T4 treatment increased the expression of BMP4/Smad4 proteins in the offspring of $\mathrm{SCH}$ pregnant rats

Real-time quantitative PCR, immunohistochemistry and Western blotting were used to detect the BMP4 and Smad4 mRNA and protein levels of the offspring's myocardium in $\mathrm{SCH}$ pregnant rats. The results showed that the mRNA levels of BMP4 and Smad4 in myocardial tissues of the offspring in the $\mathrm{SCH}$ group were significantly lower than that in the Sham group. Furthermore, L-T4 treatment significantly increased the expression of BMP4 and Smad4 mRNA in myocardial tissues of the offspring in the LT4-E10 and LT4-E13 groups (Fig. 6a-b, compared to $\mathrm{SCH}$ group, $p<0.05)$. The results of Western blotting analysis showed that the levels of BMP4 and Smad4 proteins in myocardial tissues of the offspring in the $\mathrm{SCH}$ groups were significantly lower than that in the Sham group, while L-T4 treatment significantly increased the expression of BMP4 and Smad4 proteins in both LT4-E10 and LT4-E13 groups (Fig. 6c-d, $p<0.05$ ). Immunohistochemical staining showed that BMP4 and Smad4 were mainly located in the cytoplasm and nucleus of myocardial cells. The number of BMP4- and Smad4-positive myocardial cells in the offspring in $\mathrm{SCH}$ group was significantly lower than that in the Sham group. Similarly, L-T4 treatment significantly increased the number of BMP4- and Smad4-positive myocardial cells in the LT4-E10 and LT4-E13 groups (Fig. 6e-f, compared to $\mathrm{SCH}$ group, $p<0.05)$. The results suggest that L-T4 regulates the cardiac development of the offspring in $\mathrm{SCH}$ pregnant rats by activating BMP4/ Smad4 signal pathway.

\section{Discussion}

Some studies have shown that the offspring of $\mathrm{SCH}$ pregnant rats were often accompanied by neurodevelopmental abnormalities, and early intervention with L-T4 can alleviate the neurodevelopmental abnormalities. However, it is not clear whether the offspring of $\mathrm{SCH}$ pregnant rats have cardiac developmental abnormalities, and whether L-T4 early intervention can improve the abnormalities of the offspring in $\mathrm{SCH}$ pregnant rats. The results of this study revealed that L-T4 treatment significantly decreased the serum TSH expression level in $\mathrm{SCH}$ pregnant rats, increased the heart weight and heart/body weight ratio of the offspring in $\mathrm{SCH}$ pregnant rats, improved the metabolic function of myocardial cells, and alleviated the pathological changes of myocardial tissues. In addition, L-T4 significantly increased the mRNA and proteins expression of Gata4, Nkx2-5, BMP4, and Smad4 of the offspring in $\mathrm{SCH}$ pregnant rats. The results suggest that L-T4 early intervention regulates the cardiac development of the offspring in $\mathrm{SCH}$ pregnant rats by activating BMP4/Smad4 signaling pathway, and then increasing the expression of Gata4 and Nkx2-5 proteins.

When pregnant women have hypothyroidism, abnormal thyroid hormone levels can severely affect the development of neuromotor, auditory, cardiovascular, and 


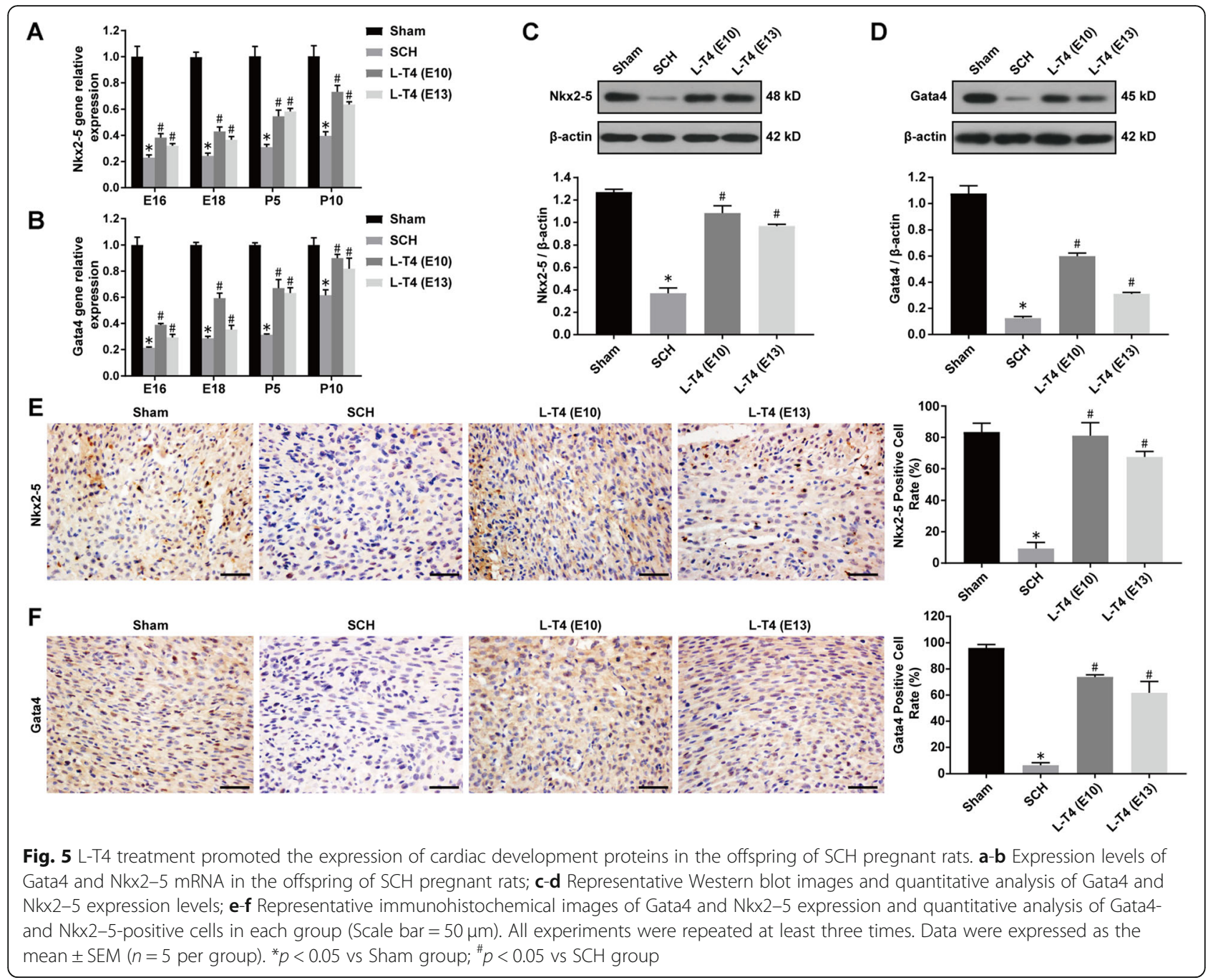

respiratory systems [15]. Thyroid hormones can promote the transformation of fetal cardiomyocytes from proliferation to hypertrophy and differentiation during full-term and early pregnancy [16]. Since the thyroid function of pregnant women affects the growth and maturation of fetal organs, the birth weight of the baby can indirectly reflect the level of thyroid function of pregnant women [17]. When the concentration of fetal thyroid hormone is kept within a relatively narrow range, it will not affect the normal development of the heart [18].Similarly, the concentration of T4 in umbilical cord blood was positively correlated with the birth weight and height of the baby, because thyroid hormones can provide nutrition and oxygen signals to the fetus in the uterus to regulate fetal growth [19]. Therefore, fetal thyroid hormone is essential for the increase of fetal weight and differentiation of specific cell types at the critical stage of development. Moreover, SCH caused growth retardation of fetal rats in the uterus, and even led to abortion or premature delivery [13] and permanent neurological defects of the offspring [20, 21]. In this study, we found that L-T4 early intervention not only significantly decreased the serum $\mathrm{TSH}$ levels in the $\mathrm{SCH}$ pregnant rats, but also increased the heart weight and heart/body weight ratio of the offspring, improved the metabolic function of myocardial cells of the offspring, and alleviated the pathological changes of myocardial tissues of the offspring. It was reported that thyroid hormone deficiency affected the expression profiles of myomiR network in the heart of fetal rats and the expression of downstream targeting genes, which in turn led to increased expression of b-MHC and related cardiac dysfunction in adulthood [22]. An infant with ectopic thyroid tissue was found to have sinus bradycardia associated with congenital hypothyroidism [23]. Another study found that SCH was associated with decreased cardiac output in patients with impaired vascular smooth muscle relaxation and reduced nitric oxide level. These changes were related to the decreased expression of sarcoplasmic reticulum $\mathrm{Ca}^{2+}$-ATPase and the inhibition of expression of ATP enzyme phosphoprotein 


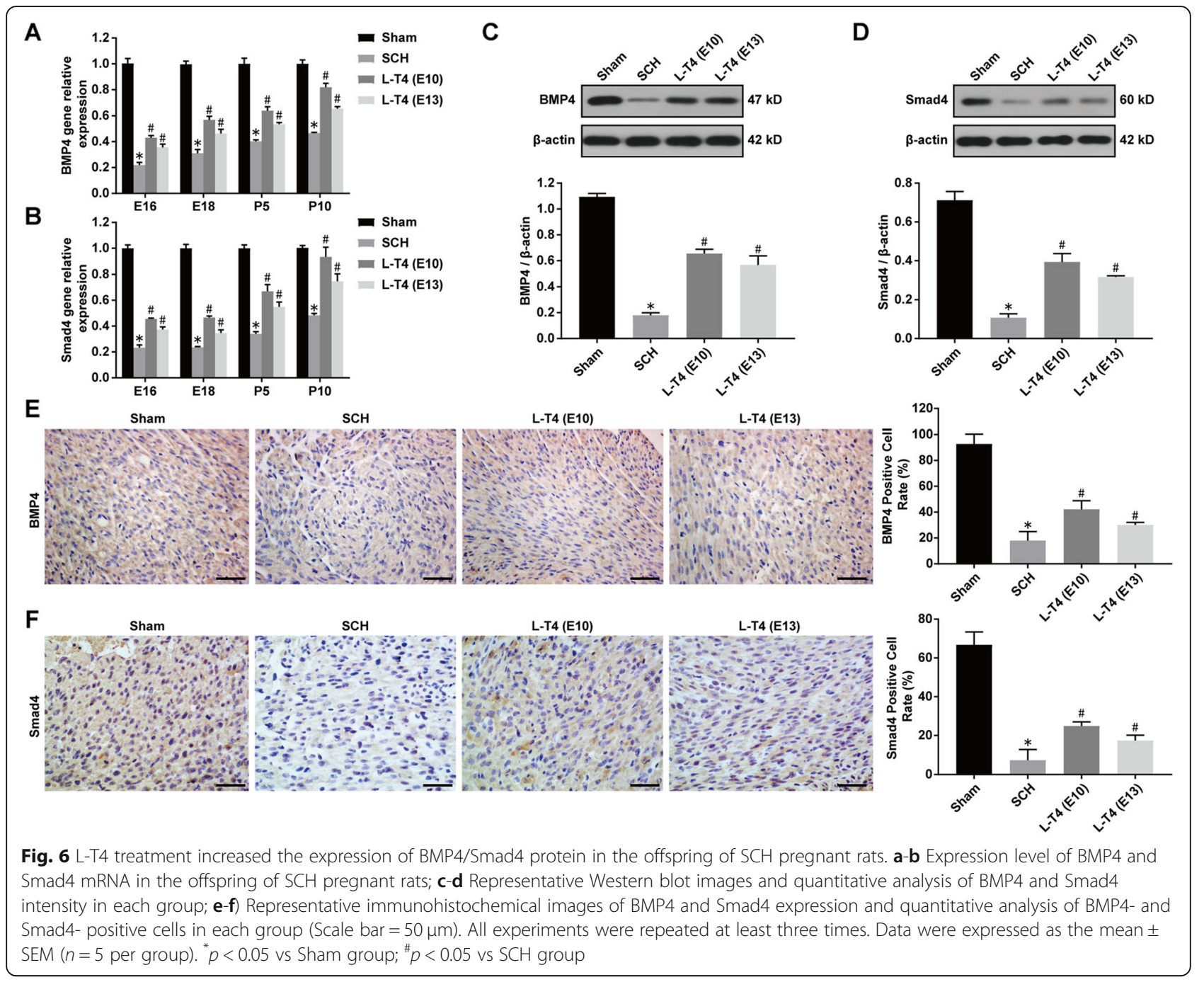

[24]. Low circulating levels of thyroid hormone inhibited the activity of sarcoplasmic reticulum calcium ATP enzyme, which controlled the contraction and relaxation cycle through ATPase, leading to myocardial stiffness and eventually left ventricular diastolic dysfunction [25]. In addition, L-T4 treatment significantly improved low density lipoprotein, total cholesterol, hypertension, diastolic dysfunction and delayed arteriosclerosis in patients with SCH [26]. These results suggest that L-T4 treatment can improve the cardiac development of the offspring in $\mathrm{SCH}$ pregnant rats, which was related to increasing the heart weight, improving the metabolic function of the cardiomyocytes and alleviating the pathological changes of cardiomyocytes.

During the early development of embryonic heart, many genes such as bone morphogenetic proteins (BMPs), fibroblast growth factor and activin/nodule are involved in heart development and differentiation [27, 28]. BMP signaling pathway played a central role in the induction of mesoderm and heart development. The BMP ligand binds to type II receptor and then activates type I receptor to phosphorylate Smad1, Smad5 or Smad8 signal transduction pathway regulated by BMP receptor [29]. When BMP is released from the receptor complex, the phosphorylated $\mathrm{R}$-Smad binds to the common Smad4 to form a trimeric complex composed of two R-Smad and Smad4, and then induces the transcription of downstream genes [30]. BMP4 knockout Fetal mice died within 9.5 days after birth, and most of them had little or no mesoderm differentiation [31]. BMP4 can induce the expression of Nkx25 and Gata4 in cardiac progenitor cells, which is necessary for cardiac development and differentiation [32]. Gata4 is one of the key transcription factors in fetal heart development. Abnormal expression of Gata4 can cause various fetal heart malformations, such as septal defect, tetralogy of Fallot, myocardial trabecular dysplasia, and valve malformation [33-35]. In this study, our results showed that the mRNA and protein expression levels of Gata4, Nkx25, BMP4, and Smad4 of the offspring were significantly decreased in $\mathrm{SCH}$ pregnant rats. Remarkably, L-T4 early 
intervention not only significantly increased the mRNA and protein levels of Gata4 and Nkx2-5, but also activated the BMP4/Smad4 signaling pathway in the myocardium of the offspring of $\mathrm{SCH}$ pregnant rats. It was reported that exposure of pregnant rats to di (2-ethylhexyl) phthalate caused cardiac malformation in the offspring, which may be related to the inhibition of cardiac Gata $4 / \mathrm{mef} 2 \mathrm{c} / \mathrm{ch}$ expression [36]. Similarly, the potential toxicity of PM2.5 to fetal heart tissue was related to the down-regulation of transcriptional factors Gata4 and $\mathrm{Nkx} 2-5$, which were functionally associated with to embryonic heart development and abnormalities of fetal heart structure and function [37]. Moreover, exposure of pregnant rats to PM2.5 aggravated cardiovascular dysplasia caused by homocysteine in their offspring [38]. These results indicate that early treatment of L-T4 can significantly improve the myocardial development of the offspring of $\mathrm{SCH}$ pregnant rats, which may be related to the activation of BMP4/ Smad4 and the regulation of Gata4 and Nkx2-5 protein expression.

\section{Conclusion}

In conclusion, early administration of L-T4 can regulate the cardiac development of the offspring of $\mathrm{SCH}$ pregnant rats by activating BMP4/Smad4 signal pathway, and then increasing the expression of Gata4 and Nkx2-5.

\section{Supplementary information}

Supplementary information accompanies this paper at https://doi.org/10. 1186/s12872-020-01646-3.

\section{Additional file 1 .}

\section{Abbreviations}

SCH: Subclinical hypothyroidism; PPARy: Peroxisome proliferator-activated receptor gamma; LT4-E10 group: L-T4 treatment started on the 10th day of gestation; SDH: Succinate dehydrogenase; T4: Thyroid hormone thyroxine; TSH: Thyroid-stimulating hormone; BMPs: Bone morphogenetic proteins

\section{Acknowledgments}

Not applicable.

\section{Authors' contributions}

DX and JY designed experiments, and wrote the manuscript. JLS revised and polished the manuscript. DX completed animal experiment, pathological experiment, molecular biology experiment and protein experiment. All authors read and approved the final manuscript.

\section{Funding}

The study was supported by the PLA foundation of Key issues of logistical support department of the Central Military Commission (BWS16J010). The funding sources had no involvement in study design; data collection, analysis and interpretation; or report writing.

\section{Availability of data and materials}

The datasets generated and analysed during the current study are not publicly available due the principle of confidentiality of funding, but are available from the corresponding author on reasonable request.
Ethics approval and consent to participate

The study was approved by the Animal Care and Use Committee of the Northern Theater General Hospital.

\section{Consent for publication}

Not applicable.

\section{Competing interests}

The authors declare that there are no conflicts of interest.

\section{Author details}

1Department of Cardiovascular Ultrasound, The First Hospital of China Medical University, No.115, Nanjing Road, HePing District, Shenyang 110001, China. ${ }^{2}$ Department of Cardiovascular Ultrasound, General Hospital of Northern Theater Command, Shenyang, China. ${ }^{3}$ Department of Gynaecology and Obstetrics, General Hospital of Northern Theater Command, Shenyang, China.

Received: 20 April 2020 Accepted: 31 July 2020

Published online: 14 August 2020

\section{References}

1. Wu T, Flowers JW, Tudiver F, Wilson JL, Punyasavatsut N. Subclinical thyroid disorders and cognitive performance among adolescents in the United States. BMC Pediatr. 2006:6:12.

2. Teng W, Shan Z, Patil-Sisodia K, Cooper DS. Hypothyroidism in pregnancy. Lancet Diabetes Endocrinol. 2013;1(3):228-37.

3. Chan S, Boelaert K. Optimal management of hypothyroidism, hypothyroxinaemia and euthyroid TPO antibody positivity preconception and in pregnancy. Clin Endocrinol. 2015;82(3):313-26.

4. Santos OC, Silva NA, Vaisman M, Turano MD, Dytz MG, Huber GA, Braulio VB, Teixeira PF. Evaluation of epicardial fat tissue thickness as a marker of cardiovascular risk in patients with subclinical hypothyroidism. J Endocrinol Investig. 2015:38(4):421-7.

5. Biondi B, Cappola AR, Cooper DS. Subclinical hypothyroidism: a review. JAMA. 2019;322(2):153-60.

6. Bielecka-Dabrowa A, Godoy B, Suzuki T, Banach M, von Haehling S. Subclinical hypothyroidism and the development of heart failure: an overview of risk and effects on cardiac function. Clin Res Cardiol. 2019; 108(3):225-33.

7. Cappola AR, Desai AS, Medici M, Cooper LS, Egan D, Sopko G, Fishman Gl, Goldman S, Cooper DS, Mora S. Thyroid and cardiovascular disease research agenda for enhancing knowledge, prevention, and treatment. Circulation. 2019;13:10.

8. Tayal B, Graff C, Selmer C, Kragholm KH, Kihlstrom M, Nielsen JB, Olsen AS, Pietersen AH, Holst AG, Sogaard P. Thyroid dysfunction and electrocardiographic changes in subjects without arrhythmias: a crosssectional study of primary healthcare subjects from Copenhagen. BMJ Open. 2019;9(6):e023854.

9. Alexander EK, Marqusee E, Lawrence J, Jarolim P, Fischer GA, Larsen PR. Timing and magnitude of increases in levothyroxine requirements during pregnancy in women with hypothyroidism. N Engl J Med. 2004;351(3):241-9.

10. Cerbone M, Capalbo D, Wasniewska M, Mattace Raso G, Alfano S, Meli R, De Luca F, Salerno M. Cardiovascular risk factors in children with long-standing untreated idiopathic subclinical hypothyroidism. J Clin Endocrinol Metab. 2014:99(8):2697-703.

11. Nakova W, Krstevska B, Kostovska ES, Vaskova O, Ismail LG. The effect of levothyroxine treatment on left ventricular function in subclinical hypothyroidism. Arch Endocrinol Metab. 2018;62(4):392-8.

12. Arslan D, Buyukinan M, Uysal C, Deniz CD. Evaluation of cardiovascular risk by growth-differentiation factor-15 and tissue Doppler imaging in children with subclinical hypothyroidism. Endocrine. 2019;65(3):601-7.

13. Shan L, Zhou Y, Peng S, Wang X, Shan Z, Teng W. Implantation failure in rats with subclinical hypothyroidism is associated with LIF/STAT3 signaling. Endocr Connect. 2019;8(6):718-27.

14. Ansari MY, Ahmad N, Haqqi TM. Butein activates autophagy through AMPK TSC2/ULK1/mTOR pathway to inhibit IL-6 expression in IL-1beta stimulated human chondrocytes. Cell Physiol Biochem. 2018;49(3):932-46.

15. Forhead AJ, Fowden AL. Thyroid hormones in fetal growth and prepartum maturation. J Endocrinol. 2014;221(3):R87-R103. 
16. Chattergoon NN. Thyroid hormone signaling and consequences for cardiac development. J Endocrinol. 2019;242(1):T145-60.

17. Thornburg K, Jonker S, O'Tierney P, Chattergoon N, Louey S, Faber J, Giraud $\mathrm{G}$. Regulation of the cardiomyocyte population in the developing heart. Prog Biophys Mol Biol. 2011;106(1):289-99.

18. Miller TA. Growth in congenital heart disease: outcome or predictor? J Am Heart Assoc. 2018;7(17):e010262.

19. Ribeiro LGR, Silva JF, Ocarino NM, Souza CA, Melo EG, Serakides R. Excess maternal thyroxine alters the proliferative activity and angiogenic profile of growth cartilage of rats at birth and weaning. Cartilage. 2018;9(1):89-103.

20. Zhang F, Chen J, Lin X, Peng S, Yu X, Shan Z, Teng W. Subclinical hypothyroidism in pregnant rats impaired learning and memory of their offspring by promoting the p75(NTR) signal pathway. Endocr Connect. 2018;7(5):688-97.

21. Ge JF, Xu YY, Qin G, Cheng JQ, Chen FH. Resveratrol ameliorates the anxiety- and depression-like behavior of subclinical hypothyroidism rat: possible involvement of the HPT Axis, HPA axis, and Wnt/beta-Catenin pathway. Front Endocrinol (Lausanne). 2016;7:44

22. Yousefzadeh N, Jeddi S, Ghiasi R, Alipour MR. Effect of fetal hypothyroidism on MyomiR network and its target gene expression profiles in heart of offspring rats. Mol Cell Biochem. 2017;436(1-2):179-87.

23. Nakanomori A, Nagano N, Seimiya A, Okahashi A, Morioka I. Fetal sinus bradycardia is associated with congenital hypothyroidism: an infant with ectopic thyroid tissue. Tohoku J Exp Med. 2019;248(4):307-11.

24. Udovcic M, Pena RH, Patham B, Tabatabai L, Kansara A. Hypothyroidism and the heart. Methodist Debakey Cardiovasc J. 2017;13(2):55-9.

25. Rodondi N, Bauer DC, Cappola AR, Cornuz J, Robbins J, Fried LP, Ladenson PW, Vittinghoff E, Gottdiener JS, Newman AB. Subclinical thyroid dysfunction, cardiac function, and the risk of heart failure. J Am Coll Cardiol. 2008;52(14):1152-9.

26. Peeters RP. Subclinical hypothyroidism. N Engl J Med. 2017;376(26):2556-65.

27. Liu W, Deng Z, Zeng Z, Fan J, Feng Y, Wang X, Cao D, Zhang B, Yang L, Liu B. Highly expressed BMP9/GDF2 in postnatal mouse liver and lungs may account for its pleiotropic effects on stem cell differentiation, angiogenesis, tumor growth and metabolism. Genes Dis. 2020;7(2):235-44.

28. Zhou C, Yan Q, Zou QY, Zhong XQ, Tyler CT, Magness RR, Bird IM, Zheng J. Sexual dimorphisms of preeclampsia-dysregulated transcriptomic profiles and cell function in fetal endothelial cells. Hypertension. 2019;74(1):154-63.

29. Chang H, Huylebroeck D, Verschueren K, Guo Q, Matzuk MM, Zwijsen A. Smad5 knockout mice die at mid-gestation due to multiple embryonic and extraembryonic defects. Development. 1999:126(8):1631-42.

30. Garside VC, Chang AC, Karsan A, Hoodless PA. Co-ordinating Notch, BMP, and TGF- $\beta$ signaling during heart valve development. Cell Mol Life Sci. 2013; 70(16):2899-917

31. Wang J, Greene SB, Martin JF. BMP signaling in congenital heart disease: new developments and future directions. Birth Defects Res A Clin Mol Teratol. 2011;91(6):441-8

32. Takei S, Ichikawa H, Johkura K, Mogi A, No H, Yoshie S, Tomotsune D, Sasaki K. Bone morphogenetic protein-4 promotes induction of cardiomyocytes from human embryonic stem cells in serum-based embryoid body development. Am J Physiol Heart Circ Physiol. 2009;296(6):H1793-803.

33. Kardon G, Ackerman KG, McCulley DJ, Shen Y, Wynn J, Shang L, Bogenschutz E, Sun X, Chung WK. Congenital diaphragmatic hernias: from genes to mechanisms to therapies. Dis Model Mech. 2017;10(8):955-70.

34. Yuan SM. Fetal arrhythmias: genetic background and clinical implications. Pediatr Cardiol. 2019;40(2):247-56.

35. He A, Gu F, Hu Y, Ma Q, Ye LY, Akiyama JA, Visel A, Pennacchio LA, Pu WT. Dynamic GATA4 enhancers shape the chromatin landscape central to heart development and disease. Nat Commun. 2014;5:4907.

36. Tang C, Deng Y, Duan H, Zhang Y, Li Y, Qiu D, Zhou K, Hua Y, Wang C. The effect of maternal exposure to di-(2-ethylhexyl)-phthalate on fetal cardiac development in mice. J Appl Toxicol. 2018;38(6):834-42.

37. Carter DR, Buckle AD, Tanaka K, Perdomo J, Chong BH. Art27 interacts with GATA4, FOG2 and NKX2.5 and is a novel co-repressor of cardiac genes. PLoS One. 2014;9(4):e95253.

38. Chen $H$, Chen $X$, Hong $X$, Liu C, Huang $H$, Wang Q, Chen S, Chen $H$, Yang $K$, Sun Q. Maternal exposure to ambient PM2.5 exaggerates fetal cardiovascular maldevelopment induced by homocysteine in rats. Environ Toxicol. 2017;32(3):877-89.

\section{Publisher's Note}

Springer Nature remains neutral with regard to jurisdictional claims in published maps and institutional affiliations.

\section{Ready to submit your research? Choose BMC and benefit from:}

- fast, convenient online submission

- thorough peer review by experienced researchers in your field

- rapid publication on acceptance

- support for research data, including large and complex data types

- gold Open Access which fosters wider collaboration and increased citations

- maximum visibility for your research: over $100 \mathrm{M}$ website views per year

At BMC, research is always in progress.

Learn more biomedcentral.com/submissions 